\title{
Peran Zakat dalam Pemberdayaan Ekonomi Mustahiq
}

\author{
Putri Rafa Nafisah*, Noviani \\ Prodi Ilmu Ekonomi, Fakultas Ekonomi dan Bisnis, Universitas Islam \\ Bandung, Indonesia.
}

*putrirafa97@gmail.com, Noviani@yahoo.com

\begin{abstract}
West Bandung Regency as one of the pemekaran districts in West Java, where the poverty rate in West Bandung Regency in 2017 stands at 11.49. While the average in West Java is 8.71. From the perspective of shari'a law in relation to community empowerment, there are several ways to overcome poverty, namely by creating employment by using zakat funds as capital to create an industry that will accommodate a number of revenues channeled to msutahiq as a means of helping venture capital.The purpose of this study is to determine the role of zakat in economic empowerment mustahiq seen from the aspects of revolving capital, economic strengthening, strengthening human resources, providing infrastructure and partnerships between MSMEs. The research method used is quantitative descriptive method. The population in this study was 73 mustahiq.
\end{abstract}

Keywords: Economic Empowerment, Poverty, Zakat

Abstrak.Kabupaten Bandung Barat sebagai salah satu kabupaten pemekaran di Jawa Barat, dimana angka kemiskinan Kabupaten Bandung Barat pada tahun 2017 berada pada angka 11,49. Sedangkan rata-rata di Jawa Barat yaitu 8,71. Ditinjau dari sudut pandang hukum kesyariahan dalam kaitannya dengan pemberdayaan masyarakat, maka terdapat beberapa cara dalam menanggulangi kemiskinan yaitu dengan menciptakan lapangan kerja dengan menggunakan dana zakat yang dijadikan modal untuk menciptakan industri yang akan menampung sejumlah penerimaan yang disalurkan kepada mustahiq sebagai sarana untuk perbantuan modal usaha.Tujuan penelitian ini untuk mengetahui peran zakat dalam pemberdayaan ekonomi mustahiq yang dilihat dari aspek modal bergulir, penguatan ekonomi, penguatan SDM, penyediaan prasarana dan kemitraan antar UMKM. Metode penelitian yang digunakan yaitu metode deskriptif kuantitatif. Populasi dalam penelitian ini yaitu sebanyak 73 mustahiq

Kata Kunci: Pemberdayaan Ekonomi, Kemiskinan, Zakat 



\section{A. Pendahuluan}

Pembangunan merupakan suatu proses multidimensional yang melibatkan perubahanperubahan besar dalam struktur sosial, sikap mental yang sudah terbiasa dan lembaga-lembaga nasional termasuk pula percepatan atau akselerasi pertumbuhan ekonomi, pengurangan ketimpangan, dan pemberantasan kemiskinan yang absolut. (Todaro, 2008).

Di sisi lain, adanya permasalahan kemiskinan dan ketidakmerataan pendapatan juga akan menghambat laju pertumbuhan ekonomi itu sendiri. Selain itu, kemiskinan dan ketidakmerataan pendapatan juga akan memberikan dampak instabilitas sosial, ketidakpastian, dan tragedi kemanusiaan seperti kelaparan, tingkat kesehatan yang rendah dan gizi buruk. Bila keadaan tersebut terus berlanjut pada akhirnya akan mengganggu stabilitas ekonomi makro dan kelangsungan pemerintahan yang ada. (Dewanto dkk, 2014).

Masalah kemiskinan merupakan masalah sosial manusia, kemiskinan bukan hal yang baru terjadi dan tidak dapat dipungkiri bahwa kemiskinan merupakan musuh terbesar dari setiap bangsa dan dampak dari kemiskinan terhadap masyarakat umumnya begitu banyak. Kemiskinan merupakan keadaan dimana ketidakmampuan untuk memenuhi kebutuhan dasar seperti pakaian, makanan, tempat tinggal, pendidikan dan kesehatan. Islam menghendaki setiap individu hidup ditengah-tengah masyarakat secara layak sebagai manusia yaitu sekurang-kurangnya dapat memenuhi kebutuhan pokok berupa sandang dan pangan, memperoleh pekerjaan dan mampu membina keluarganya. (Fatmawati, 2017).

Di Indonesia kemiskinan merupakan masalah sosial yang senantiasa relevan untuk di kaji terus menerus. Hal ini juga dikarenakan Indonesia merupakan salah satu negara yang sedang berkembang dengan jumlah penduduk yang terus meningkat setiap tahun, sehingga tingkat kesejahteraan rakyatnya masih jauh di bawah tingkat kesejahteraan negara-negara maju. (Suharto,2009).

Jumlah penduduk miskin terbanyak di Indonesia berada di Pulau Jawa. Provinsi Jawa Barat merupakan daerah yang tergolong memiliki tingkat kemiskinan yang tinggi. Salah satu pemicu tingginya tingkat kemiskinan yaitu banyaknya jumlah penduduk sedangkan ruang yang tersedia sempit. Berikut data Jumlah Penduduk Miskin Menurut Kabupaten di Jawa Barat Tahun 2015-2017 :

Tabel 1.1 Jumlah Penduduk Miskin Menurut Kabupaten di Jawa Barat (Tahun 2015-2017)

\begin{tabular}{|l|c|c|c|}
\hline \multirow{2}{*}{\multicolumn{1}{|c|}{ Nama Wilayah }} & \multicolumn{3}{|c|}{ Jumlah Penduduk Miskin Kabupaten } \\
\cline { 2 - 4 } & $\mathbf{2 0 1 5}$ & $\mathbf{2 0 1 6}$ & $\mathbf{2 0 1 7}$ \\
\hline Indramayu & 14,98 & 13,95 & 13,67 \\
\hline Kuningan & 13,97 & 13,59 & 13,27 \\
\hline Majalengka & 14,19 & 12,85 & 12,6 \\
\hline Cirebon & 14,77 & 13,49 & 12,97 \\
\hline Bandung Barat & $\mathbf{1 2 , 6 7}$ & $\mathbf{1 1 , 7 1}$ & $\mathbf{1 1 , 4 9}$ \\
\hline Cianjur & 12,21 & 11,62 & 11,41 \\
\hline Garut & 12,81 & 11,64 & 11,27 \\
\hline Tasikmalaya & 11,99 & 11,24 & 10,84 \\
\hline Subang & 12,27 & 11,05 & 10,77 \\
\hline Bogor & 8,96 & 8,83 & 8,57 \\
\hline Sukabumi & 8,96 & 8,13 & 8,04 \\
\hline Bandung & 8,00 & 7,61 & 7,36 \\
\hline Ciamis & 8,98 & 8,42 & 8,2 \\
\hline Sumedang & 11,36 & 10,57 & 10,53 \\
\hline Purwakarta & 9,14 & 8,98 & 9,06 \\
\hline Karawang & 10,37 & 10,07 & 10,25 \\
\hline Bekasi & 5,27 & 4,92 & 4,73 \\
\hline Pangandaran & 10,76 & 10,23 & 10,00 \\
\hline & & & \\
& \multicolumn{3}{|c}{}
\end{tabular}

Dari Tabel 1.1 terlihat bahwa posisi presentase kemiskinan Kabupaten Bandung Barat berada pada peringkat ke lima setelah Kabupaten Cirebon. Presentase jumlah penduduk miskin di Kabupaten Bandung Barat dari tahun ke tahun mengalami penurunan. Pada tahun 2017 kondisi kemiskinan di Kabupaten Bandung Barat mengalami penurunan dari tahun 2016 sebesar 0,22\%. Meskipun Kabupaten Bandung barat memiliki jumlah penduduk miskin yang rendah dibandingkan dengan kabupaten yang lainnya, tetapi kemiskinan di Kabupaten Bandung Barat harus dapat ditanggulangi agar tidak mengalami kenaikan kembali, sehingga tercipta pemerataan kesejahteraan masyarakat di Kabupaten Bandung Barat.

Kabupaten Bandung Barat sebagai salah satu kabupaten pemekaran di Jawa Barat, dimana tujuan dari pemekaran yaitu untuk percepatan peningkatan pelayanan dan kesejahteraan 
masyarakat, namun selama 11 tahun terbentuknya Kabupaten Bandung Barat, tujuan itu masih jauh dari harapan. Angka kemiskinan Kabupaten Bandung Barat pada tahun 2017 berada di angka 11,49. Sedangkan rata-rata di Jawa Barat yaitu 8,71 (pikiranrakyat.com). Dikarenakan mayoritas penduduk kabupaten bandung barat beragama Islam maka zakat merupakan salah satu solusi untuk meningkatkan kesejahteraan masyarakat, diantaranya bisa melalui zakat produktif.

\section{B. Landasan Teori}

Zakat berasal dari kata "zaka" yang berarti suci, berkah, baik, tumbuh dan berkembang.dinamakan zakat, karena di dalamnya terkandung harapan untuk beroleh berkat, membersihkan jiwa dan memupuknya dengan berbagai kebaikan (Sabiq, 1971). Kata zakat ditinjau dari segi Bahasa mempunyai pengertian berkah, tumbuh, bersih dan baik. Makna lain dari kata zakat, sebagaimana digunakan dalam al-Qur' an adalah suci dari dosa. Perkataan zakat diartikan dengan suci, tumbuh dan berkembang. Ada delapan asnaf sebagaimana terdapat dalam Al-Qur'an surat At-Taubah ayat 60.

Zakat merupakan salah satu rukun Islam, zakat diwajibkan di Madinah pada bulan Syawal tahun kedua Hijriyah setelah diwajibkannya puasa Ramadhan dan zakat fitrah, didalam Al-Qur'an terdapat dua puluh tujuh ayat yang menyejajarkan kewajiban zakat dalam berbagai bentuk kata (Ali, 1988:90). Zakat merupakan kewajiban bagi orang beriman (muzakki) yang mempunyai harta yang telah mencapai mencapai ukuran tertentu (nisab) dan waktu tertentu (haul) untuk diberikan kepada orang yang berhak (mustahiq). Sedangkan kewajiban zakat dalam Islam memiliki makna yang sangat fundamental, saling berkaitan erat dengan aspek-aspek ke Tuhan, juga ekonomi sosial (Nuruddin, 2006:1). Sebagai rukun ketiga dari rukun Islam zakat juga menjadi salah satu diantara pundi-pundi Islam yang tidak boleh diabaikan oleh siapa pun juga.

Menurut Asnaini (2009) banyak sekali hikmah yang terkandung dalam melaksanakan zakat. Zakat merupakan ibadah yang memiliki dimensi ganda, vertical dan horizontal. Artinya secara vertical, zakat sebagai ibadah dan wujud ketakwaan dan kesyukuran seorang hamba kepada Allah SWT atas nikmat berupa harta yang diberikan Allah kepadanya serta untuk membersihkan dan mensucikan diri dan hartanya itu. Dalam konteks inilah zakat bertujuan untuk menghubungkan manusia dengan Tuhan. Sedangkan secara horizontal, zakat bertujuan mewujudkan rasa keadilan sosial dan kasih saying di antara pihak yang mampu dengan pihak yang tidak mampu dan dapat memperkecil problema dan kesenjangan sosial serta ekonomi umat. Dalam konteks ini zakat diharapkan dapat mewujudkan pemerataan dan keadilan sosial diantara kehidupan umat manusia, terutama Islam.

Dalam hal ini, para ulama telah membahas mengenai apa hikmah dan tujuan dari adanya zakat. Di antaranya, menurut Yusuf Qardhawy (2005), secara umum terdapat dua tujuan dari ajaran zakat, yaitu untuk kehidupan individu dan untuk kehidupan sosial kemasyarakatan. Tujuan pertama meliputi pensucian jiwa dari sifat kikir, mengembangkan sifat suka memberi, mengobati hati dari cinta dunia, mengembangkan kekayaan batin dan menumbuhkan rasa simpati dan cinta sesame manusia. Dengan ungkapan lain, esensi dari semua tujuan ini adalah memperkaya jiwa manusia dengan nilai-nilai spiritual yang dapat meningkatkan harkat dan martabat manusia. 


\section{Hasil Penelitian dan Pembahasan}

\section{Uji Validitas dan Reliabilitas}

Tabel 3.1 Uji Validitas

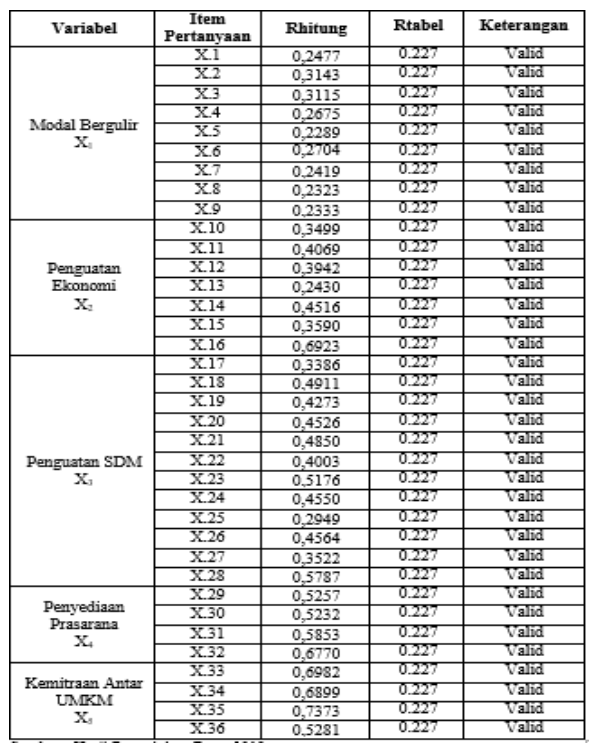

Tabel 3.2 Uji Realibilitas

\begin{tabular}{c|c|c|c|c|}
\hline Variabel & Cornbach's Alpha & N of Items & R Tabel & Keterangan \\
\hline Mustahiq & 0,874231 & 36 & 0,329 & Reliabel \\
\hline
\end{tabular}

Berdasarkan tabel diatas, hasil uji validitas, diperoleh hasil bahwa pada masing-masing sub variabel pada variabel pemberdayaan ekonomi masyarakat memiliki nilai koefesien realibilitas $>0.329$, sehingga dapat disimpulkan bahwa masing-masing sub variabel tersebut reliabel

\section{Aspek Modal Bergulir}

Tabel 3.3 Tanggapan Mustahiq Mengenai Aspek Modal Bergulir.

\begin{tabular}{|c|c|c|c|c|c|c|c|c|}
\hline \multirow[b]{2}{*}{ No } & \multirow[b]{2}{*}{ Pernyataan } & \multicolumn{5}{|c|}{ Frekuensi Pernyataan } & \multirow{2}{*}{$\begin{array}{l}\text { Nilai } \\
\text { Skor }\end{array}$} & \multirow{2}{*}{$\begin{array}{c}\text { Skala } \\
\text { Interpretasi }\end{array}$} \\
\hline & & $\begin{array}{l}\text { SS } \\
(5)\end{array}$ & \begin{tabular}{|c|} 
S \\
$(4)$
\end{tabular} & \begin{tabular}{|l} 
CS \\
(3)
\end{tabular} & \begin{tabular}{|l|} 
TS \\
$(2)$ \\
\end{tabular} & \begin{tabular}{|c|} 
STS \\
$(1)$
\end{tabular} & & \\
\hline 1 & $\begin{array}{l}\text { Bantuan modal usaha yang } \\
\text { diberikan sudah tepat sasaran } \\
\text { dalam memberikan bantuan } \\
\text { modal usaha }\end{array}$ & 17 & 32 & 22 & 2 & 0 & 283 & $\mathrm{~s}$ \\
\hline 2 & $\begin{array}{l}\text { BapakikTbu mendapatkan } \\
\text { bantuan modal usaha sesuai } \\
\text { dengan yang dibutuhkcan }\end{array}$ & 10 & 14 & 18 & 28 & 3 & 219 & $\mathrm{cs}$ \\
\hline 3 & $\begin{array}{l}\text { Bantuan modal usaha sebagai } \\
\text { modal utama untuk bisa } \\
\text { menialankan yagha }\end{array}$ & 9 & 24 & 21 & 15 & 4 & 238 & $\mathrm{CS}$ \\
\hline 4 & $\begin{array}{l}\text { Persyaratan bantuan modal } \\
\text { usaha yang diberikan mudah } \\
\text { dipenuhi }\end{array}$ & 7 & 24 & 20 & 16 & 6 & 229 & $\mathrm{CS}$ \\
\hline 5 & $\begin{array}{l}\text { Prosedur untuk mendapatkan } \\
\text { bantuan modal usaha tidak } \\
\text { berbelit-belit }\end{array}$ & 8 & 28 & 22 & 11 & 4 & 244 & $\mathrm{cs}$ \\
\hline 6 & $\begin{array}{l}\text { Proses pemberian bantuan } \\
\text { modal usaha yang diberikan } \\
\text { kepada masyarakat penerima } \\
\text { bantuan cepat jika telah } \\
\text { memenuhi persyaratan }\end{array}$ & 9 & 29 & 22 & 11 & 2 & 251 & $\mathrm{~s}$ \\
\hline 7 & $\begin{array}{l}\text { Tepat wakktu dalam } \\
\text { memberikan bantuan modal } \\
\text { kepada masyarakat yang } \\
\text { menerima bantuan modal usaha }\end{array}$ & 8 & 20 & 19 & 23 & 3 & 226 & $\mathrm{CS}$ \\
\hline 8 & $\begin{array}{l}\text { Bantuan zakat yang diberikan } \\
\text { sebagai modal untuk memulai } \\
\text { usaha mengembangkan usaha }\end{array}$ & 10 & 28 & 24 & 11 & 0 & 256 & $\mathrm{~s}$ \\
\hline 9 & $\begin{array}{l}\text { Bapak Tbu dapat } \\
\text { mengembalikan modal usaha } \\
\text { yang telah diberikan dalam } \\
\text { jangka walktu yang telah } \\
\text { ditentukan }\end{array}$ & 14 & 32 & 20 & 6 & 1 & 271 & $\mathrm{~s}$ \\
\hline
\end{tabular}


Berdasarkan hasil keseluruhan pada aspek Penguatan Ekonomi dinyatakan bahwa dari sembilan indikator mendapat total skor sebesar 1.898 dengan rata-rata skor sebesar 271,14. Aspek Penguatan Ekonomi mendapat skala interpretasi setuju.

\section{Aspek Penguatan Ekonomi}

Tabel 3.4 Tanggapan Mustahiq Mengenai Aspek Penguatan Ekonomi

\begin{tabular}{|c|c|c|c|c|c|c|c|c|}
\hline \multirow[b]{2}{*}{ NO } & \multirow[b]{2}{*}{ Pernyataan } & \multicolumn{5}{|c|}{ Frekuensi Pernyataan } & \multirow{2}{*}{$\begin{array}{l}\text { Nilai } \\
\text { Skor }\end{array}$} & \multirow{2}{*}{$\begin{array}{c}\text { Skala } \\
\text { Interprestas }\end{array}$} \\
\hline & & $\begin{array}{l}\text { SS } \\
\text { (5) }\end{array}$ & $\begin{array}{c}S \\
(4)\end{array}$ & $\begin{array}{l}\mathrm{CS} \\
\text { (3) }\end{array}$ & $\begin{array}{l}\text { TS } \\
\text { (2) }\end{array}$ & $\begin{array}{l}\text { STS } \\
\text { (1) }\end{array}$ & & \\
\hline 1 & $\begin{array}{l}\text { Bantuan modal ugaha } \\
\text { mampumemberikan mean } \\
\text { peluang untuk } \\
\text { pengembangan usaha }\end{array}$ & 7 & 47 & 13 & 6 & 0 & 274 & $\mathrm{~s}$ \\
\hline 2 & $\begin{array}{l}\text { Bantuan modal usaha } \\
\text { mampun meningkatkan } \\
\text { penghasilan }\end{array}$ & 13 & 41 & 14 & 5 & 0 & 281 & $\mathrm{~s}$ \\
\hline 3 & $\begin{array}{l}\text { Bantuan modal usaha } \\
\text { mampu menstabilkan } \\
\text { komdisi ekonomi } \\
\text { keluarga melalui usaha } \\
\text { yang dijalankan }\end{array}$ & 8 & 47 & 13 & 5 & 0 & 277 & $s$ \\
\hline 4 & $\begin{array}{l}\text { Bantuan modal usaha } \\
\text { yamg diberikan dapat } \\
\text { membukca lapangan } \\
\text { pekerjaan bagi } \\
\text { bapak/ibu }\end{array}$ & 12 & 38 & 17 & 6 & 0 & 275 & $s$ \\
\hline 5 & $\begin{array}{l}\text { Bantuan modal ugaha } \\
\text { dapat meningkatkan } \\
\text { status sosial keluarga di } \\
\text { lingkungan masyarakcat }\end{array}$ & 16 & 24 & 27 & 5 & 1 & 268 & $\mathrm{~s}$ \\
\hline 6 & $\begin{array}{l}\text { Bantuan modal usaha } \\
\text { yang diterima digunakan } \\
\text { untuk memperbaiki } \\
\text { elkonomi menjadi lebih } \\
\text { baik }\end{array}$ & 12 & 43 & 13 & 5 & 0 & 281 & $s$ \\
\hline 7 & $\begin{array}{l}\text { Setelah mendapatkan } \\
\text { bantuan modal usahha, } \\
\text { gaudara bisa bersaing } \\
\text { dalam menjalankan } \\
\text { usaha }\end{array}$ & 8 & 26 & 24 & 11 & 4 & 242 & $\mathrm{cs}$ \\
\hline
\end{tabular}

Berdasarkan hasil keseluruhan pada aspek Penguatan Ekonomi dinyatakan bahwa dari sembilan indikator mendapat total skor sebesar 1.898 dengan rata-rata skor sebesar 271,14. Aspek Penguatan Ekonomi mendapat skala interpretasi setuju.

\section{Aspek Penguatan Sumber Daya Manusia}

Tabel 3.5 Tanggapan Mustahiq Aspek Penguatan Sumber Daya Manusia

\begin{tabular}{|c|c|c|c|c|c|c|c|c|}
\hline \multirow[b]{2}{*}{ No } & \multirow[b]{2}{*}{ Penyataan } & \multicolumn{5}{|c|}{ Frekuensi Pernyataan } & \multirow{2}{*}{$\begin{array}{l}\text { Nilai } \\
\text { Skor }\end{array}$} & \multirow{2}{*}{$\begin{array}{c}\text { Skala } \\
\text { Interpretasi }\end{array}$} \\
\hline & & $\begin{array}{l}\text { SS } \\
\text { (5) }\end{array}$ & $\begin{array}{c}S \\
\text { (4) }\end{array}$ & $\begin{array}{l}\mathrm{CS} \\
\text { (3) } \\
\end{array}$ & \begin{tabular}{l|} 
TS \\
(2)
\end{tabular} & $\begin{array}{l}\text { STS } \\
\text { (1) }\end{array}$ & & \\
\hline 1 & $\begin{array}{l}\text { Mensogialisasikan } \\
\text { bantuan modal usaba } \\
\text { gecara merata kepada } \\
\text { peneriman bentuan }\end{array}$ & 12 & 34 & 26 & 1 & 0 & 276 & s \\
\hline 2 & $\begin{array}{l}\text { Memberikan pengarahan } \\
\text { kepada masyarakat dalum } \\
\text { berwirausaha }\end{array}$ & 10 & 30 & 30 & 3 & 0 & 266 & s \\
\hline 3 & $\begin{array}{l}\text { Memberikan pelatihan } \\
\text { agar mustahiq berjiwa } \\
\text { terampil, kreatif serta } \\
\text { mandiri }\end{array}$ & 11 & 28 & 27 & 7 & 0 & 262 & s \\
\hline 4 & $\begin{array}{l}\text { Bantuan modal uscha } \\
\text { yang diberikan disertai } \\
\text { dengan bantuan pelatihan } \\
\text { usaha kepada } \\
\text { masyarakat, sehingga } \\
\text { masyarakat berhasil } \\
\text { dalam berwirasuaha }\end{array}$ & 18 & 27 & 22 & 6 & 0 & 276 & $\mathrm{~s}$ \\
\hline 5 & $\begin{array}{l}\text { Ada pengawasan yang } \\
\text { dilakukan pihak } \\
\text { BAZNAS terhadap usaha } \\
\text { yang dilaksaunkan } \\
\text { bapalkibu yang } \\
\text { memperoleh bantuan } \\
\text { modal usahn }\end{array}$ & 22 & 23 & 21 & 7 & 0 & 279 & s \\
\hline 6 & $\begin{array}{l}\text { Adarya bimbingan } \\
\text { berkala dalam } \\
\text { mengembangkan usaba } \\
\text { terhadap bapak ibu yang } \\
\text { mendapatakan bantuan } \\
\text { modal usaha }\end{array}$ & 21 & 23 & 23 & 6 & 0 & 278 & S \\
\hline 7 & $\begin{array}{l}\text { Bantuan modal usgha } \\
\text { membantu meningkatkan } \\
\text { kualitas SDM dalam } \\
\text { berwirausaha }\end{array}$ & 15 & 21 & 28 & 8 & 1 & 260 & S \\
\hline 8 & $\begin{array}{l}\text { Bapalk Tou mudah } \\
\text { menerapkan pelatihan } \\
\text { yang telah diberikan }\end{array}$ & 14 & 23 & 24 & 10 & 2 & 256 & S \\
\hline
\end{tabular}

JRIEB is licensed under Creative Commons Attribution- 
Berdasarkan hasil keseluruhan pada aspek penguatan sumber daya manusia dinyatakan bahwa dari sembilan indikator mendapat total skor sebesar 3.194 dengan rata-rata skor sebesar 266,1. Aspek modal bergulir mendapat skala interpretasi setuju.

\section{Aspek Penyedia Prasarana}

Tabel 3.6 Tanggapan Mustahiq mengenai Aspek Penyedia Prasarana

\begin{tabular}{|c|c|c|c|c|c|c|c|c|}
\hline \multirow{2}{*}{ NO } & \multirow{2}{*}{ Pernyataan } & \multicolumn{5}{|c|}{ Frekuensi Pernyataan } & \multirow{2}{*}{$\begin{array}{l}\text { Nilai } \\
\text { Skor }\end{array}$} & \multirow{2}{*}{$\begin{array}{c}\text { Skala } \\
\text { Interprestasi }\end{array}$} \\
\hline & & $\begin{array}{l}\text { SS } \\
(5)\end{array}$ & \begin{tabular}{c|}
$S$ \\
$(4)$
\end{tabular} & $\begin{array}{l}\text { CS } \\
\text { (3) }\end{array}$ & $\begin{array}{l}\text { TS } \\
(2)\end{array}$ & $\begin{array}{c}\text { STS } \\
\text { (1) }\end{array}$ & & \\
\hline 1 & $\begin{array}{l}\text { Memberikan bantuan } \\
\text { berupa barang-barang } \\
\text { usaha }\end{array}$ & 7 & 19 & 22 & 22 & 3 & 224 & $\mathrm{CS}$ \\
\hline 2 & $\begin{array}{l}\text { Memberikan bantuan } \\
\text { berupa sarana yang } \\
\text { membantu bapak/ibu } \\
\text { dalam menjalankan } \\
\text { usaha }\end{array}$ & 8 & 22 & 23 & 17 & 3 & 234 & $\mathrm{CS}$ \\
\hline 3 & $\begin{array}{l}\text { Memberikan bantuan } \\
\text { berupa tempat untuk } \\
\text { membantu bapak/ibu } \\
\text { dalam menjalankan } \\
\text { usaha }\end{array}$ & 5 & 21 & 21 & 21 & 5 & 219 & $\mathrm{CS}$ \\
\hline 4 & $\begin{array}{l}\text { Bapak/ibu memiliki } \\
\text { sarana produksi usaha } \\
\text { berupa mesin mesin } \\
\text { penunjang usaha }\end{array}$ & 7 & 29 & 24 & 10 & 3 & 246 & $\mathrm{CS}$ \\
\hline
\end{tabular}

Berdasarkan hasil keseluruhan pada aspek penyediaan prasarana dinyatakan bahwa dari sembilan indikator mendapat total skor sebesar 923 dengan rata-rata skor sebesar 230,7. Aspek penyediaan prasarana mendapat skala interpretasi cukup setuju.

\section{Aspek Kemitraan antar UMKM}

Tabel 3.7 Tanggapan mustahiq mengenai aspek kemitraan antar UMKM

\begin{tabular}{|c|c|c|c|c|c|c|c|c|}
\hline \multirow[b]{2}{*}{ NO } & \multirow[b]{2}{*}{ Pernyataan } & \multicolumn{5}{|c|}{ Frekuensi Pernyataan } & \multirow{2}{*}{$\begin{array}{l}\text { Nilai } \\
\text { Skor }\end{array}$} & \multirow{2}{*}{$\begin{array}{c}\text { Skala } \\
\text { Interprestasi }\end{array}$} \\
\hline & & $\begin{array}{l}\text { SS } \\
\text { (5) }\end{array}$ & \begin{tabular}{|c|}
$S$ \\
$(4)$ \\
\end{tabular} & \begin{tabular}{|l|} 
CS \\
$(3)$ \\
\end{tabular} & \begin{tabular}{|l|} 
TS \\
$(2)$ \\
\end{tabular} & \begin{tabular}{|c|} 
STS \\
$(1)$ \\
\end{tabular} & & \\
\hline 1 & $\begin{array}{l}\text { Setelah mendapatkan } \\
\text { bantuan modal usaha, } \\
\text { bapak/ibu menjalin } \\
\text { kemitraan dengan } \\
\text { sesama pelaku usaha }\end{array}$ & 8 & 25 & 23 & 14 & 3 & 240 & CS \\
\hline 2 & $\begin{array}{l}\text { Setelah mendapatkan } \\
\text { bantuan modal usaha } \\
\text { dari BAZNAS KBB, } \\
\text { bapak/ibu menjalin } \\
\text { kemitraan dengan } \\
\text { koperasi }\end{array}$ & 7 & 29 & 23 & 12 & 2 & 246 & CS \\
\hline 3 & $\begin{array}{l}\text { Dengan menjalin } \\
\text { kemitraan } \\
\text { mempermudah dalam } \\
\text { pengadaan bahan baku }\end{array}$ & 9 & 28 & 22 & 11 & 3 & 248 & CS \\
\hline 4 & $\begin{array}{l}\text { Dengan menjalin } \\
\text { kemitraan, akses } \\
\text { pemasaran usaha } \\
\text { menjadi lebih luas } \\
\text { melalui supplier } \\
\text { seperti menjalin } \\
\text { kemitraan dengan } \\
\text { agen atau grosir }\end{array}$ & 9 & 27 & 24 & 12 & 1 & 250 & $\mathrm{~S}$ \\
\hline
\end{tabular}

Berdasarkan hasil keseluruhan indikator pada aspek kemitraan antar UMKM, maka diperoleh total skor sebesar 984 dengan rata-rata skor sebesar 246. Aspek kemitraan antar UMKM mendapat skala interpretasi cukup beperan.

\section{Kesimpulan}

1. Aspek Penguatan Ekonomi berada pada skala nterpretasi berperan dengan rata-rata skor 271,1. Berdasarkan data yang didapat bahwa bantuan modal yang mustahiq yang 
diterima sangat berguna dikarenakan dapat mempserbaiki dari segi ekonomi dan meningkatkan status sosial mustahiq tersebut di lingkungan masyarakat mereka tinggal

2. Aspek sumber daya manusia berada pada skala interpretasi berperan dengan rata-rata skor 266,1. Berdasarkan data yang didapat bahwa mustahiq sangat terbantu dikarenakan pengetahuan mereka menjadi bertambah untuk menjalankan usaha.

3. Aspek Bantuan Modal Bergulir berada pada skala interpretasi cukup berperan dengan rata-rata skor 245,5. Berdasarkan data yang telah didapat bahwasanya dengan adanya bantuan modal bergulir, tingkat perekonomian mustahiq di Kabupaten Bandung Barat menjadi meningkat.

4. Aspek Kemitraan Antar UMKM berada pada skala interpretasi cukup berperan dengan rata-rata skor 246. BAZNAS cukup membantu mustahiq dngan memberikan bantuan berupa relasi supplier agen maupun grosir untuk para mustahiq agar mudah mendapatkan bahan baku yang mereka butuhkan sehingga relasi para mustahiq pun menjadi luas.

5. Aspek Penyediaan Prasarana berada pada skala interpretasi cukup berperan dengan ratarata skor 230,7. Selain menyediakan modal dan pelatihan, BAZNAS juga memberikan prasarana berupa tempat usaha maupun alat produksi demi menunjang kelancaran usaha mustahiq.

\section{Daftar Pustaka}

[1] Todaro. 2008. "Pembangunan yang melibatkan Perubahan Struktur Sosial".

[2]Dewanto,dkk .2014.'Permasalahan kemiskinan dan ketidakmerataan pendapatan juga akan menghambat laju pertumbuhan ekonomi".

[3] Fatmawati, 2017."Masalah kemiskinan merupakan masalah sosial manusia"

[4] https://scholar.google.com/scholar?hl=en\&as_sdt=0\%2C5\&q=Suharto\%2C2009\&btnG= 